\title{
ARSIP FOTO UNIVERSITAS DIPONEGORO SEBAGAI MEMORI KORPORAT: LANDASAN DIGITALISASI ARSIP FOTO
}

\author{
Tri Handayani*, Amin Taufiq Kurniawan** \\ *Program Studi Kearsipan Fakultas Ilmu Budaya Undip \\ **Program Studi Ilmu Perpustakaan Fakultas Ilmu Budaya Undip \\ Jl. Prof. Soedarto, SH Tembalang Ï Semarang 50275 \\ Email: tri.handayani.undip@gmail.com \\ amintaufiq@yahoo.com
}

\begin{abstract}
This paper discusses about digitalization of Diponegoro University' courtesy photo archives. These efforts done through transferring conventional photo to electronic media, and then to perform it on website. Finally, as concluding remark that photo archives management base on website become quicker and easier of archives retrival possible.
\end{abstract}

Keywords: digitalization of photo archives, corporate memory, Diponegoro University

\section{PENDAHULUAN}

Salah satu bentuk arsip yang memegang peranan penting bagi perkembangan sebuah institusi adalah arsip foto. Arsip foto adalah dokumen yang dapat menggambarkan tentang perjalanan historis individu atau institusi, begitu pula dengan arsip foto yang dimiliki oleh Universitas Diponegoro (Undip). Perjalanan Undip sebagai institusi pendidikan tinggi tergambarkan secara sistematis dan kronologis melalui arsip foto. Tetapi, meskipun keberadaan arsip foto begitu penting bagi perjalanan sejarah institusi, tetapi pengelolaan arsip foto yang diciptakan di lingkungan Undip belum sistematis sebagaimana seharusnya suatu memori korporat diperlakukan.

Kemajuan teknologi informasi membawa pengaruh pada media foto. Pada era ini orang cenderung menggunakan kamera digital, sehingga fisik negatif film digantikan oleh negative film digital atau elektronik. Arsip ini merupakan informasi yang disimpan pada media elektronik atau digital. Daur hidup arsip elektronik mempunyai tahapan yang sama dengan arsip kertas (konvensional) yaitu tahap penciptaan, pemeli-haraan, penggunaan, penyusutan, dan diciptakan lagi sebagai memori korporat.(Robert, 1993: 386)

Pembuatan pemrograman arsip foto dengan sistem elekronik file (Electronic Filing System) sebagai model pengelolaan kearsipan sangat membantu dalam bidang kearsipan.Electronic Filing System merupakan sistem perekaman kertas menjadi electronic file dengan berbagai ukuran yang dapat disimpan di dalam hard disk atau optical disk. Keuntungan menggunakan Electronic Filing System adalah tingkat yang semakin cepat dalam mengakses informasi, dan tingkat akurasi data yang diakses.

Penggunaan sistem arsip foto elektronik juga dapat dimanfaatkan untuk mengalihmediakan arsip yang berupa foto (hardcopy) menjadi arsip elektronik (softcopy), sehingga manajemen kearsipan foto akan memudahkan dalam menata, mengatur dan merawat arsip yang mereka miliki. Hal ini sejalan dengan Undang- 
HUMANIKA Vol. 19 No. 1 (2014) ISSN 1412-9418

Arsip Foto Universitas Diponegoro sebagai Memori Korporat

Tri Handayani, Amin Taufiq Kurniawan

Undang Nomor 8 Tahun 1999 yang mengatur legalitas arsip elektronik, mulai dari tata cara pengalihan media hingga ke tata cara pemusnahan arsip elektronik. Sistem kearsipan elektronik pada arsip foto adalah penggunaan media elektronik dalam pengelolaan arsip yang berbasis pada penggunaan komputer dan web (Sugiarto dan Wahyono, 2005: 123) yang dapat mempercepat penemuan dan menghemat dalam pengelolaan arsip sehingga lebih efektif dan efisien. Pendapat ini sejalan dengan pendapat Roberts (1993: 390)

Penelitian ini berupaya menginventarisasi arsip foto Undip. Selain itu penelitian ini juga melakukan alih media arsip foto dari tekstual ke dalam bentuk elektronik file serta membuat program temu balik arsip foto yang berbasis web. Melalui tahapan tersebut maka arsip foto Undip dapat terkelola secara baik sekaligus temu balik arsip menjadi lebih cepat dan efisien. Oleh karena itu, studi ini akan mengangkat pertama, bagaimana inventariasi arsip foto Universitas Diponegoro. Kedua, bagaimana langkahlangkah digitalisasi atau alih media arsip foto dari bentuk tekstual ke bentuk elektronik file; Ketiga, bagaimana upaya aplikatif pembuatan program temu balik arsip foto yang berbasis web. Melalui upaya yang terpadu ini diharapkan pengelolan arsip foto dapat dilakukan secara baik dan temu balik arsip menjadi cepat dan mudah.

Penelitian tentang Arsip Foto

Universitas Diponegoro sebagai Memori Korporat: Landasan Digitalisasi Arsip Fotomerupakan sebuah penelitian deskriptif analitis dengan dukungan data kualitatif. Penelitian ini menggunakan sumber primer berupa arsip foto. Sumber primer selain berupa arsip foto juga berasal dari hasil wawancara ter-hadap pihak-pihak yang mengetahui kondisi arsip foto. Metode penelitian yang lain adalah observasi. Dari observasi ini terlihat secara faktual kondisi arsip foto. Dalam rangka menggali informasi yang berkaitan dengan pengelolaan arsip foto. Observasi atau pengamatan bertujuan untuk memperoleh deskripsi yang lebih utuh mengenai kondisi riil. Potret penataan, penanganan, dan pengelolaan kearsipan memperkaya pengetahuan dan pemahaman untuk melakukan tahapan berikutnya.

Metode lain adalah wawancara terhadap para pihakyang terlibat dalam pengelolaan arsip foto. Wawancara ini bertujuan untuk mengetahui kondisi arsip foto Universitas Diponegoro dari waktu ke waktu. Terutama berkaitan dengan jumlah arsip dan pengelolaan kearsipan mulai dari proses terciptanya arsip hingga penyimpanan, pemeliharanan, serta temu balik arsip. Data penelitian dikumpulkan dengan menggunakan teknik wawan-cara mendalam. Populasi penelitian dengan menggunakan wawancara dilakukan terhadap semua elemen pemangku kepentingan (stakeholder) yang memiliki kepedulian dan komitmen terhadap arsip foto termasuk pengguna arsip foto. Wawancara mendalam (depth interview) dilakukan untuk mengetahui dan memahami fenomena-fenomena tertentu yang diperlukan sebagai data, misalnya untuk mengetahui jumlah arsip foto, sejarah dari arsip foto, fungsi dan makna arsip foto bagi institusi. Termasuk fungsinya sebagai memori kolektif civitas akademika. Data-data yang berasal dari wawancara tersebut dikomparasikan dan di-cross check secara kritis berkaitan dengan kredibi-litasnya informasi yang disampaikan.

Selain sumber primer, penelitian ini juga mengacu pada sumber sekunder. Sumber sekunder ini dilakukan melalui pencarian data dan hasil penelitian sebelumnya berupa studi pustaka. Studi pustaka digunakan sebagai studi komparasi dalam menjelaskan fenomenafenomena yang sama atau memiliki kemiripan dengan obyek kajian penelitian, tetapi berbeda lokasi ataupun periodisasi waktunya. 
Setelah deskripsi integral tentang tata kelola arsip foto dilakukan, maka tahapan selanjutnya adalah melakukan alih media arsip foto konvensional ke dalam bentuk elektronik. Tahapan yang lain adalah melakukan kegiatan pemrograman satu persatu terhadap arsip foto yang ada di Universitas Diponegoro. Pemrograman ini menggunakan program yang berbasis pada $w e b$.

\section{HASIL DAN PEMBAHASAN}

\section{A. Arsip Foto sebagai Memori Korporat}

Informasi memiliki berbagai makna tergantung pada ilmu yang membahasnya. Informasi dikatakan memiliki berbagai tolok ukur dan ancangan keilmuan yang sangat dipengaruhi antara definisi yang satu dengan definisi yang lain. Menurut Sulistyo-Basuki (2003: 3) akibat terlalu banyaknya definisi informasi, maka untuk memahami informasi sebaiknya kita melihatnya dari segi pemahaman bukan dari segi definisi.

Informasi didahului oleh sebuah peristiwa. Peristiwa ini diwakili dalam bentuk symbol-simbol yang disusun menurut peraturan dan konvensi yang merupakan data. Data ini dapat berupa data numeric (angka), tekstual (berupa huruf), audio berupa suara atau bunyi, video berupa gambar, citra atau gabungan antara dua jenis data atau lebih. Bila data tersebut diterima manusia melalui panca inderanya maka data tersebut berubah menjadi informasi. Bila informasi tersebut disebarluaskan ke individu lain maka konsep informasi berubah menjadi pengetahuan selama informasi tersebut merupakan hal yang baru bagi penerima. Apabila si penerima memperoleh informasi baru, maka bagi si penerima infor-masi tersebut menjadi memperoleh pengetahuan.

Informasi yang diterima manusia dapat dikategorikan menjadi 2 jenis informasi terekam dan informasi tidak terekam dalam media tertentu. Misalnya, seseorang menulis surat kepada $\mathrm{B}$, maka informasi yang diterima oleh $B$ merupakan informasi terekam. Bila A berbisik kepada $\mathrm{B}$, maka bisikan tersebut merupakan informasi yang tidak terekam dalam sebuah media (kertas, elektronik) tetapi tercatat di benak B.

Informasi yang dibuat manusia maupun badan korporasi (perusahaan, departemen, instansi, yayasan, dan sejenisnya) dapat berupa informasi terekam dan dapat pula berupa informasi tak terekam. Informasi terekam ini dapat dibagi menurut jenis medianya seperti media grafis, media elektronik, dan audio visual. Media grafis berarti informasi direkam dalam bentuk grafis dan dicetak. Contohnya buku, majalah,, laporan, formulir. Bila direkam dalam bentuk elektronik maka untuk menyimpan dan membacanya memerlukan perlatan khusus. Contoh kaset, piringan hitam. Audio visual adalah informasi terekam yang dapat dipandang dan didengar dengan menggunakan peralatan khusus. Contoh film, video, VHS. Contoh lain adalah Globe. Globe atau bola dunia tidak dimasukkan ke kelompok media grafis karena memang tidak dicetak. Menurut Sulistyo-Basuki (2003:4) apapun bentuknya, informasi terekam merupakan dokumen.

Dengan kata lain, dokumen adalah informasi terekam dengan tidak memandang medianya. Istilah dokumen sinonim dengan rekaman. Sehingga pemahaman tentang informasi baik yang dikaji oleh disiplin ilmu perpustakaan, dokumentasi, kearsipan adalah mengacu pada jenis informasi terekam dalam berbagai medium. Informasi terekam inilah yang menjadi objek formal awal paradigm ilmu informasi yang kemudian didiferensiasi menjadi bidang keilmuan tentang dokumen. Berkaitan dengan rekaman dokumen dalam konteks Memori Korporat, Megill (2005: 26) berpendapat:

"Corporate memory is one of the organization's most important 
HUMANIKA Vol. 19 No. 1 (2014) ISSN 1412-9418

Arsip Foto Universitas Diponegoro sebagai Memori Korporat

Tri Handayani, Amin Taufiq Kurniawan

assets. It encompasses all of the many types of documented and undocumented information that organizational units require to function effectively. This information is used throughout the organization, from executive management through the finance, legal and personnel departments, to those involved in the engineering, manufacturing and marketing activities. Much of the corporate memory is normally reflected in documents that consist of information packages which are products of the work of the organization. These packages come in many forms: they may be reports, letters, electronic mail messages or databases. They may contain elements stored throughout the organization in various media. Later we will look more closely at the new document that is one of the results of the electronic age."

Menurut Sulistyo-Basuki (2003: 46) berikut adalah alasan utama mengapa manusia sebagai individu maupun bagian dari kelompok, merekam informasi:

1. Alasan pribadi; individu cenderung memproduksi informasi yan menyangkut kapasitas pribadi, individu, dan keluarga yang berupa dokumen bermakna dalam kehidupan kehidupan. Manusia menulis surat, membuat puisi, mengarang buku, membuat pidato, dan menyusun silsilah. Dokumen yang lebih bermakna misalnya akte kelahiran, surat nikah, dan surat kematian. Dokumen ini dapat berupa kertas, rekaman gambar, atau rekaman suara.

2. Alasan Sosial; manusia tidak hidup sendiri, melainkan dalam sebuah kelompok (komunitas). Manusia merupakan bagian dari organisasi sosial yang berdasarkan minat bersama akan menghasilkan rekaman tentang kegiatan mereka, baik sebagai perorangan maupun bagian dari organisasi sosial. Sebagai contoh, untuk menjadi anggota sebuah lingkungan masyarakat, seseorang perlu mendaftarkan diri, membuat kartu tanda penduduk, dan kartu keluarga. Kegiatan politis menghasilkan rekaman berupa keuangan organisasi, rapat pimpinan, kampanye, pemilihan ketua umum,dsb. 3. Alasan ekonomi, individu maupun badan korporasi yang menghasilkan uang, mengelola, dan membelanjakannya akan menghasilkan data terekam yang berguna bagi perorangan maupun badan korporasi sebagai kepentingan pribadi ataupun kolektif. Rekaman informasi tersebut perlu untuk mengetahui kondisi berbagai macam aktivitas perekonomian yang telah dilakukan. Berbagai macam dokumen dibuat misal kwitansi, faktur pajak, daftar gaji, laporan keuangan, buku induk, neraca, dsb.

4. Alasan Hukum; badan pemerintah merupakan perekam informasi untuk berbagai kepentingan. Rekaman informasi ini digunakan untuk berbagai keperluan, misalnya untuk melindungi dan melayani masyarakat. Rekaman informasi untuk alasan hukum ini memperjelas fungsi hak dan kewajiban individu maupun badan korporasi. Dokumen yang menjadi contoh adalah segala rekaman tertulis yang dihasilkan atau dikumpulkan oleh pengadilan (perdata, pidana, administrasi, militer) terutama dalam konteks system hukum Indonesia

5. Alasan Instrumental; banyak rekaman informasi diproduksi dan dirancang untuk melaksanakan tugas tertentu. Hal ini terjadi karena dokumen tersebut sengaja dibuat atau karena ada. Misalnya gambar arsitektur dan cetak biru (blue print) ketika dibuat memang sudah ada tujuan instrumental. Jadi, sejak semula gambar arsitektur dibuat untuk tujuan 
HUMANIKA Vol. 19 No. 1 (2014) ISSN 1412-9418

Arsip Foto Universitas Diponegoro sebagai Memori Korporat

Tri Handayani, Amin Taufiq Kurniawan

instrumental walaupun kemudian hari tujuan instrumentalnya berubah.

6. Alasan Simbolik; beberapa rekaman informasi dibuat tidak selalu memiliki kepentingan praktis, ada kalanya kepentingan simbolik. Beberapa universitas di Eropa dan Amerika mengeluarkan ijazah yang ditulis dalam bahasa Latin, yang mungkin tidak dipahami si penerima. Dokumen ijazah tersebut merupakan symbol keberhasilan seseorang mencapai jenjang akademis.

7. Alasan Pengembangan Pengetahuan; ilmuwan yang melakukan penelitian akan menyebarkan hasil penelitiannya kepada orang lain dalam bentuk informasi terekam. Dengan demikian ilmu pengetahuan merupakan kumulasi dari pengetahuan lainnya dan kumulasi ini diwujudkan dalam bentuk informasi terekam.

Dengan demikian, maka dapat dimengerti bahwa rekaman disimpan oleh badan korporasi sebagai pencipta dan penerima informasi. Bila ditinjau dari segi informasi terekam, sebenarnya terdapat berbagai badan yang menyimpan informasi terekam. Adapun badan tersebut ialah perpustakaan, pusat rekaman (record center), depo arsip, dan museum. Karena terdapat berbagai jenis rekaman informasi yang dihasilkan dan tersebar di masyarakat maka terdapat berbagai disiplin ilmu yang mengkaji informasi terekam tersebut.

\section{B. Penanganan Arsip Foto}

Undang-Undang Nomor 43 Tahun 2009 tentang Kearsipan merupakan landasan hukum penyelenggaraan kearsipan di wilayah Negara Republik Indonesia. Arsip foto yang ditangani tim peneliti adalah foto yang diciptakan oleh UPT Humas Undip. Foto merupakan salah satu jenis recorded information (informasi terekam), maka informasi yang direkam dalam media foto berpotensi sebagai memory collective bagi penciptanya.

Arsip foto yang diciptakan oleh UPT Humas Undip menyimpan memory corporate Undip sekaligus memory collective bangsa. Berdasar pada informasi yang direkam pada media foto tersebut, kita dapat melihat lintasan peristiwa tri dharma perguruan tinggi maupun administrasi yang pernah terjadi, maupun kilasan peristiwa yang pernah dialami para civitas akademika pada momen-momen Undip yang tidak resmi dimasa yang telah lalu hingga sekarang. Namun, dari hasil pengamatan peneliti nampak, bahwa memory corporate sekaligus memory collective yang sarat dengan nilai-nilai peradaban dan perkembangan ilmu pengetahuan serta teknologi informasi tersebut hampir tidak diperdulikan oleh civitas akademika Undip. Hasil observasi di lingkungan Undip dan wawancara dengan Ibu Sriyati, S.Sos., Bapak. J. Harry, S.Kom dan Ibu Dian Komalasari, S.Kom., diketahui bahwa di setiap unit kerja di lingkungan Undip menciptakan arsip foto, tetapi mereka tidak mengelola arsip tersebut secara sistematis, sehingga mereka tidak mengetahui secara tepat letak lokasi arsip foto dan bagaimana kondisi mereka. UPT Humas Undip selaku unit kerja yang potensial menciptakan arsip foto pada saat dilakukan survey pada tahun 2009 menunjukkan kepemilikan terhadap ribuan positif foto mapun negatif foto yang luar biasa nilai informasinya. Khasanah foto yang dimiliki diciptakan dengan media foto konvensional. Namun menjelang tahun 2010 seiring dengan era teknologi informasi dibidang fotograsi, maka media penyimpan informasi berubah dalam bentuk digital. Maka, era fotografi konvensionalpun mulai ditinggalkan dan fisik media foto konvensional ñdilupakanò. Pada saat survey dilakukan sekitar tahun oleh tim dosen Program Studi Diploma III Kearsipan pada tahun 2009, menunjukkan 
HUMANIKA Vol. 19 No. 1 (2014) ISSN 1412-9418

Arsip Foto Universitas Diponegoro sebagai Memori Korporat

Tri Handayani, Amin Taufiq Kurniawan

bahwa kondisinya sangat

memprihatinkan. Indikatornya adalah:

1) Almari-almari tempat penyimpanan arsip positif foto dan negatif foto sebelum diakuisisi diletakkan di teras lantai 2 gedung rektorat tepat berdampingan dengan dinding toilet rektorat.

2) Arsip positif foto teratur disimpan dalam album-album foto. Albumalbum tersebut dimasukkan ke dalam boks foto bawaan dari album foto tersebut ketika dibeli. Album-album foto tersebut diletakkan berjajar secara vertikal di dalam lemari. Label yang memuat bulan dan tahun arsip foto yang disimpan dalam album tersebut, ditempel pada punggung luar boks foto,namun sebagian boks album foto nampak tidak dipasang label.Pada bagian cover dalam dari album foto dimuat daftar inventaris foto berdasar judul peristiwa yang diabadikan.

3) Arsip positif foto tidak teratur berada di luar album. Mereka diikat dengan kertas yang bertuliskan waktu perekaman peristiwa dengan media foto dilakukan.

4) Arsip negatif foto berada di dalam amplop cabinet. Amplop ini dibuat dibuat dari kertas. Pada badan amplop diketik daftar waktu perekaman peristiwa dengan media foto dilakukan lengkap dengan judul kegiatan. Namun ada juga negatif film yang tetap di dalam amplop bawaan dari counter cetak foto. Pada amplop tersebut dicantumkan momen peristiwa beserta waktu perekamannya.

5) Satu diantara almari-almari tersebut dimanfaatkan petugas cleaning service untuk menyimpan alat-alat perlengkapan kebersihan dalam ruangan.

6) Beberapa laci filing-filing kabinet digunakan untuk menyimpan dokumen-dokumen tekstual berupa potongan-potongan berita dari surat kabar. Tentu saja potongan-potongan artikel surat kabar tersebut merupakan materi klipping tetapi belum sempat dijilid. Selain materi klipping, di dalam laci filing cabinet dan lemari kayu juga ditemukan berbagai majalah, bulletin dari Negara Belanda yang bahkan diantaranya belum dikeluarkan dari amplop kemasan pengirimannya.

Khasanah arsip foto dan dokumen literer yang diciptakan oleh UPT Humas Undip kemudian diakuisisi ke Laboratorium Arsip Diploma III Kearsipan Fakultas Ilmu Budaya Undip. Akuisisi foto oleh Program Studi D III Kearsipan dilakukan karena Undip belum memiliki University Archives. Sementara arsip foto yang diciptakan oleh UPT Humas Undip berpotensi memiliki memory corporat Undip. Arsip dengan nilai memory corporat harus dikelola secara sistematis untuk menjamin eksistensi arsip tersebut. Dalam perkembangannya, situasi dan kondisi Fakultas Ilmu Budaya yang pada saat itu sedang dalam masa transisi pasca pindah dari kampus Undip Pleburan, menjadikan kondisi khasanah arsip foto maupun dokumen literer tidak tertangani secara maksimal. Album-album foto masih dalam keadaan dibendel dengan tali rafia. Setiap ikat terdiri dari rata-rata 10 album.

Berdasarkan hasil temuan tentang kondisi arsip Undip, maka dilakukan penanganan sebagai berikut:

1) Pemilahan antara arsip dengan non arsip.

Kegiatan penanganan arsip foto dimulai dengan pemilahan antara arsip dan non arsip. Non arsip adalah materi yang di dalam kumpulan berkas tetapi bukan arsip.

2) Pemilahan antara khasanah arsip foto dengan dokumen literer.

Kegiatan pemilahan antara khasanah arsip foto dengan dokumen literer adalah upaya untuk memudahkan proses tahap selanjutnya. 
3) Pembersihan Arsip Foto

\subsection{Pembersihan Arsip Foto Teratur}

Pembersihan merupakan tahap awal dari proses penanganan arsip foto. Dengan demikian pada tahap selanjutnya arsip sudah dalam keadaan bersih dan relatif aman bagi kesehatan pengelola arsip.

\subsection{Pembersihan Arsip Foto Tidak Teratur}

Kegiatan pembersihan arsip foto tidak teratur tujuannya sama dengan pembersihan arsip foto tidak teratur

4) Pemilahan antara arsip positif foto teratur, arsip positif foto tidak teratur, dan Arsip negatif foto.

Kegiatan pemilahan antara arsip positif foto teratur, arsip positif foto tidak teratur, dan arsip negatif foto adalah kegiatan dengan tujuan untuk memudahkan proses tahap selanjutnya.

5) Pengelompokkan arsip positif foto berdasarkan waktu penciptaannya. 5.1. Pengelompokkan arsip positiffoto teratur

Pengelompokkan arsip foto teratur adalah kegiatan mengelompokkan album-album foto berdasarkan kronologis penciptaannya. Kegiatan pengelompokkan dilakukan dengan tujuan untuk memudahkan penataan fisik album foto.

5.2. Pengelompokkan arsip positif foto tidak teratur

Foto tidak teratur adalah foto yang ketika diperoleh tidak memberkas dalam satu sistem pemberkasan tertentu. Dengan demikian diperlukan langkah pengelompokkan terlebih dahulu terhadap arsip dengan kategori ini agar mudah dalam proses tahap selanjutnya.

6) Pemilahan khasanah arsip positif foto yang akan di dideskripsikan berdasar subyek dan waktu penciptaannya.

Kegiatan pemilahan khasanah arsip positif foto berdasar subyek sebagai kklasifikasi utama dan kronologi penciptaan sebagai sub klasifikasi karena sistem penataan arsip foto lebih tepat menggunakan sistem, subyek sebagai klasifikasi utama karena orang akan lebih mudah mengingat peristiwa yang akan dicari. Setelah subyek, maka yang ditelusur pada langkah selanjutnya adalah waktu dari peristiwa itu terjadi.

7) Alih media arsip positif foto.

Alih media arsip positif foto adalah kegiatan mengalihmedia informasi yang direkam dalam bentuk positif foto ke media digital. Kegiatan alih media dilakukan dengan beberapa alat bantu. Alat bantu yang dimaksud adalah:

(1) Perangkat komputer, yaitu dalam kegiatan penelitian ini perangkat komputer merupakan mesin elektronik yang berfungsi sebagai alat baca proses dan melihat hasil alih media positif foto. Komputer digunakan sebagai perangkat untuk mengolah arsip positif foto yang sudah mengalami proses digitalisasi.

(2) Scanner, yaitu alat pemindai yang berfungsi sebagai pengalih media perekam informasi dari positif foto ke digital foto.

(3) Eksternal disk, yaitu alat penyimpan hasil alih media arsip positif foto.

8) Proses alih media arsip foto

Proses alih media arsip foto dilakukan untuk memudahkan pengguna agar lebih cepat dalam melakukan temu balik arsip foto. Hal ini karena selain pengguna menemukan lokasi arsip foto, pengguna dapat mengetahui kondisi arsip foto yang dibutuhkan. Tujuannya selain menyimpan file arsip foto digital ini adalah konten informasi yang digital ini juga terdapat dalam foto yang konvensional (sebagai media back up)

9) Pendeskripsian khasanah arsip foto hasil alih media.

Pendeskripsian khasanah arsip foto hasil alih media dilakukan dengan referensi dari narasumber dengan 
HUMANIKA Vol. 19 No. 1 (2014) ISSN 1412-9418

Arsip Foto Universitas Diponegoro sebagai Memori Korporat

Tri Handayani, Amin Taufiq Kurniawan

melalui beberapa katergori yang dibuat oleh deskriptor meliputi:

1. Jenis kegiatan yang ada di arsip foto

2. Tokoh yang muncul dalam arsip foto

3. Tanggal pelaksanaan kegiatan

4. Lokasi tempat kegiatan

5. Keterangan lain yang mampu digali dari narasumber mengenai aspek arsip foto

Proses pendeskripsian khasanah ini bertujuan mengetahui secara jelas aspek peristiwa yang muncul dari arsip foto, agar mampu memberikan deskripsi yang jelas mengenai persitiwa yang muncul sehingga merupakan entitas dari konsep memori korporat sekaligus kolektif dari Universitas Diponegoro.

10) Input Deskripsi Khasanah Arsip Foto Hasil Alih Media dalam Excel Proses input deskripsi naskah foto ini dilakukan dengan menggunakan perangkat lunak microsoft excel yang digunakan sebagai kertas kerja (worksheet) untuk menginput seluruh deskripsi khasanah foto berdasarkan kategori yang sudah ditentukan. Perlu ditekankan adalah kode dan lokasi folder dalam arsip foto digital ini juga dimasukkan dalam kertas kerja sehingga akan diperlukan dalam proses temu balik arsip foto.

11) Penyimpanan arsip positif foto ke dalam amplop.

Langkah penyimpanan arsip positif foto dalam amplop ini dilakukan dengan cara sebagai berikut:

(1) Melakukan proses penyimpanan arsip positif foto ke dalam amplop yang disusun berdasarkan Subjek dan Kronologis waktu;

(2) Khasanah arsip foto disimpan dalam amplop yang kemudian disimpan ke dalam boks arsip yang kemudian juga dikelompokkan berdasarkan urutan subjek;

(3) Khasanah arsip foto yang disimpan dalam amplop sekaligus diberi keterangan mengenai deskripsi arsip foto sesuai dengan keterangan di kertas kerja dan kategori.

12) Pelabelan boks album positif foto. Label pada boks album positif foto bertujuan untuk memudahkan pengguna agar mengetahui isi yang berada dalam boks album positif foto tersebut. Label boks album positif foto diketik menggunakan komputer yang dicetak menggunakan kertas HVS. Unsur yang berada dalam label boks album positif foto yaitu jenis arsip foto (arsip foto inaktif), pencipta arsip foto, dan nomor almari tempat penyimpanan boks album positif foto.

13) Pembuatan Sekat Album Arsip Foto

14) Penataan amplop positif foto ke dalam boks arsip.

Amplop positif foto ditata berdasar sistem subyek (sebagai main subyek). Adapun sub subyeknya berdasar sistem kronologis. Sekat dibuat dari karton berwarna dengan tujuan untuk memudahkan temu balik.

15) Penataan album positif foto ke dalam almari.

Penataan album positif foto yang tidak dipilih untuk dideskripsikan, ditata menggunakan sistem kronologis dengan ketentuan sebagai berikut:

(1) Foto yang tertua ditata di dalam almari nomor 1 dan seterusnya.

(2) Sistem penataan album pada setiap almari dimulai dari kiri atas ke kanan demikian seterusnya mengular ke bawah.

\section{Hasil Kegiatan}

Hasil kegiatan dari penelitian:

1. Antara arsip dan non arsip sudah terpilah.

2. Antara arsip dan dokumen literer sudah terpilah.

3. Arsip foto sudah tertata berdasar sistem subyek dan sistem kronologis. 
HUMANIKA Vol. 19 No. 1 (2014) ISSN 1412-9418

Arsip Foto Universitas Diponegoro sebagai Memori Korporat

Tri Handayani, Amin Taufiq Kurniawan

4. Arsip foto tidak teratur sudah ditata berdasar sistem subyek dan sistem kronologis.

5. Arsip foto sudah dideskripsikan sesuai dengan subyeknya berdasar urutan jabatan rektor.

6. Arsip foto yang sudah diseleksi berdasar nilaiguna sekunder berdasarkan masa jabatan rektor.

7. Arsip foto sudah dideskripsikan dan diinput dengan memanfaatkan program Microsof Excel berdasar subyek.

8. Fisik arsip positif foto sudah dialih media dengan format jpeg.

\section{SIMPULAN DAN SARAN}

Simpulan hasil penelitian ini bahwa belum dilakukan inventarisasi yang sistematis terhadap arsip-arsip foto Undip yang tercipta sehingga dikhawatirkan memori korporat Undip sekaligus memori kolektif bangsa akan punah. Kedua, langkah-langkah digitalisasi atau alih media arsip foto dari bentuk tekstual ke bentuk elektronik file melalui tahapan: pemilahan, pemilihan, pengelompokkan, pengalihmediaan, penamaan, penataan; Ketiga, bagai-mana upaya aplikatif pembuatan program temu balik arsip foto yang berbasis webmelalui kajian dan studi banding ke Lembaga Kearsipan Provinsi Jawa Tengah. Melalui upaya yang terpadu ini diharapkan pengelolan arsip foto dapat dilakukan secara baik dan temu balik arsip menjadi cepat dan mudah.

Berdasarkan simpulan tersebut, diajukan beberapa saran. Pertama, hasil penelitian digitalisasi arsip foto Undip menunjukkan perubahan yang cukup besar terhadap sistem pengelolaan arsip foto Undip. Namun demikian, hasil penelitian tersebut perlu ditindak lanjuti dengan upaya diseminasi kinerja Undip yang direkam dengan media foto kepada publik melalui website Undip. Langkah ini secara langsung merupakan pelaksanaan atas amanah Undang-Undang
Nomor 43 Tahun 2009 tentang Kearsipan.Kedua, tampilan khasanah arsip foto yang direkomendasikan di website Undip merupakan hasil kajian dan studi banding ke Lembaga Kearsipan Provinsi Jawa Tengah yang sudah mengunggah khasanah arsip foto yang dikelola oleh lembaga kearsipan tersebut. Pertimbangan kedua adalah, bahwa Lembaga Kearsipan Provinsi Jawa Tengah dalam pembuatan desain unsur dalam tampilan khasanah arsip foto yang mereka kelola telah melalui proses konsultasi dengan Deputi Kearsipan Daerah Arsip Nasional Republik Indonesia. Hasil dari konsultasi tersebut antara lain adanya cantuman unsur source codearea pada setiap kode khasanah arsip foto. Source code area merupakan kode unik lembaga kearsipan. Setiap lembaga kearsipan memiliki source code area sendiri-sendiri yang menunjukkan identifikasi lembaga kearsipan tertentu. Source codearea tidak hanya berlaku secara nasional, tetapi juga internasional. Setiap Arsip Perguruan Tinggi termasuk UPT Arsip Perguruan Tinggi Undip juga berhak memiliki source code area.Source code area diatur dan diterbitkan oleh Arsip Nasional Republik Indonesia selaku Pembina Kearsipan Nasional. Dengan source code area ini, setiap pengguna informasi berbasis arsip tidak terhalang oleh ruang dan waktu untuk mengakses arsip yang mereka perlukan, karena mereka dapat mengakses melalui internet dan mengetahui siapa dan dimana arsip tersebut dikelola dan disimpan. Ketiga, halamanwebsite khasanah arsip foto Undip setidaknya meliputi unsure sebagaimana berikut ini dan disetiap halaman terdapat jendela-jendela dari setiap halaman (lihat lampiran 1). 
HUMANIKA Vol. 19 No. 1 (2014) ISSN 1412-9418

Arsip Foto Universitas Diponegoro sebagai Memori Korporat

Tri Handayani, Amin Taufiq Kurniawan

\section{DAFTAR PUSTAKA}

Al-Bahra bin Ladjamudin. (2005). Analisis dan Desain Sistem Informasi, Jakarta.

Blouin, Francis $\mathrm{X}$, and William G. Roseberg. (2007). Archives, Documentation, and Institution of Social Memory: Essay From The Sawyer Seminar. Ann Harbor Michigan: The University of Michigan Press.

Cook, Michael and Margaret Procter. (1989). A Manual of Archival Description. British: Gower Publishing Company Limited.

Mudjiati, Johanna. (2007). ñStudi Pengaruh Penggunaan Sistem Informasi terhadap Kinerja Karyawan Fakultas Ekonomi Universitas Diponegoro,ò Fakultas Sastra, Skripsi mahasiswa.

Oổrien, James A. (2006). Pengantar Sistem Informasi, Jakarta.

Roberts, David. (1993). Managing Records in Special Formats (Second Edition). Victoria (Australia): DW Thorpe.

Sugiarto, Agus dan Teguh Wahyono. (2005). Manajemen Kearsipan Modern, Yogyakarta: Gaya Media.

Suhardi, Hardi dan Yayan Daryan. (1998). Terminologi Kearsipan Indonesia. Jakarta: Pustaka Sinar Harapan.

Undang-Undang RI Nomor 8 Tahun 1999 tentang Legalitas Arsip Elektronik.
Undang-Undang RI Nomor 43 Tahun 2009 tentang Kearsipan

Sulistyo-Basuki. (2003). Manajemen Arsip Dinamis: Pengantar memahami dan mengelola informasi dan dokumen. Jakarta: Gramedia Pustaka Utama.

Soejono Trimo. (1987). Dari Dokumentasi ke Sistem Infomasi Manajemen. Bandung: Remadja Rosdakarya

Sulistyo-Basuki. (1993). Pengantar Ilmu Perpustakaan. Jakarta: Gramedia

Sulistyo-Basuki. (1989). Pengantar Dokumentasi Ilmiah. Jakarta: Kesaint Blanc

Sulistyo-Basuki. (2006). ก̃nformasi, Komunikasi dan Ilmu Perpustakaan \& Informasiò dalam SulistyoBasuki dkk. Perpustakaan dan Informasi dalam Konteks Budaya. Jakarta: Departemen Ilmu Perpustakaan dan Informasi, FIB UI.

Amsyah, Zulkifli. (1990). Manajemen Kearsipan, Jakarta: Gramedia

$\begin{array}{ll}\text { Sistem Informasi, } & \text { Jakarta: }\end{array}$

Megill, Kenneth A. (2005). Corporate Memory: Records and Information Management in the Knowledge Age. Second Edition. Muechen: K.G.Saur. 
HUMANIKA Vol. 19 No. 1 (2014) ISSN 1412-9418

Arsip Foto Universitas Diponegoro sebagai Memori Korporat

Tri Handayani, Amin Taufiq Kurniawan

\section{Lampiran 1.}

a. Halaman Home

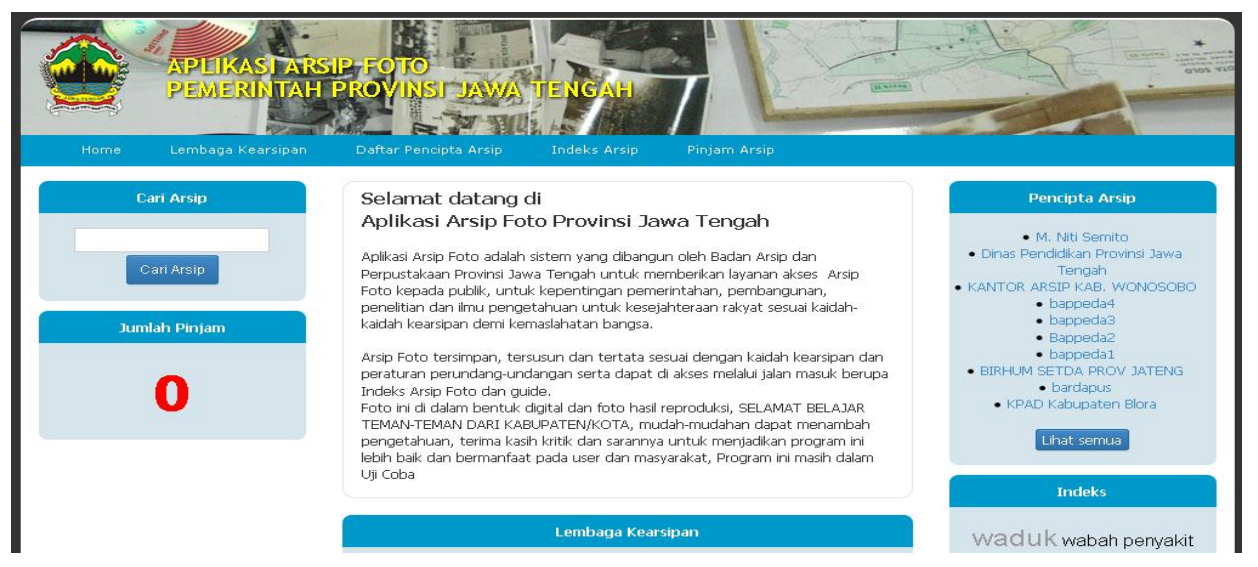

b. Halaman Daftar Lembaga Kearsipan

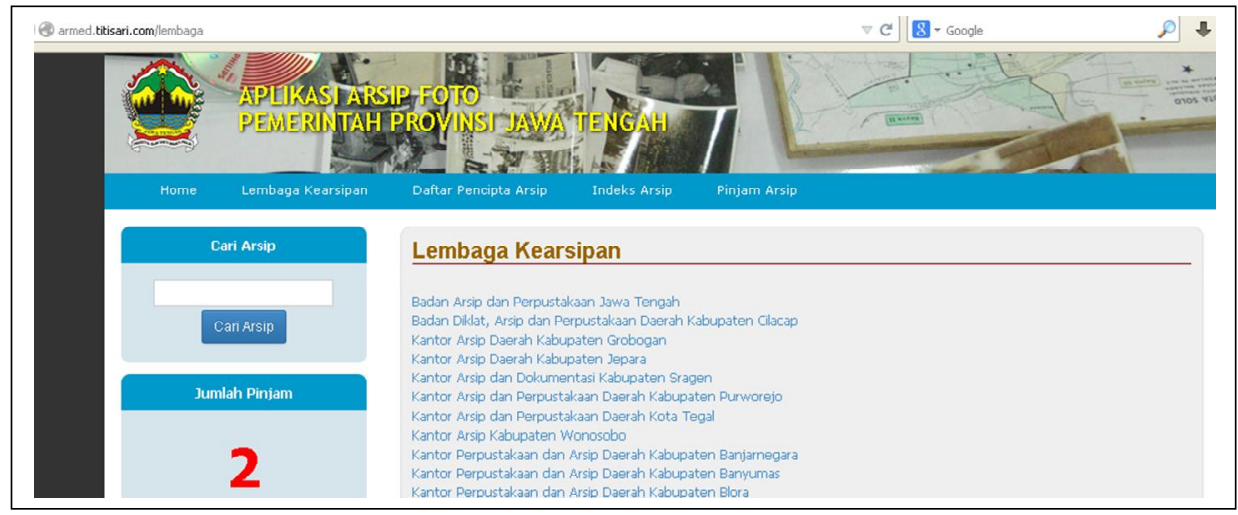

c. Halaman Daftar Pencipta Arsip

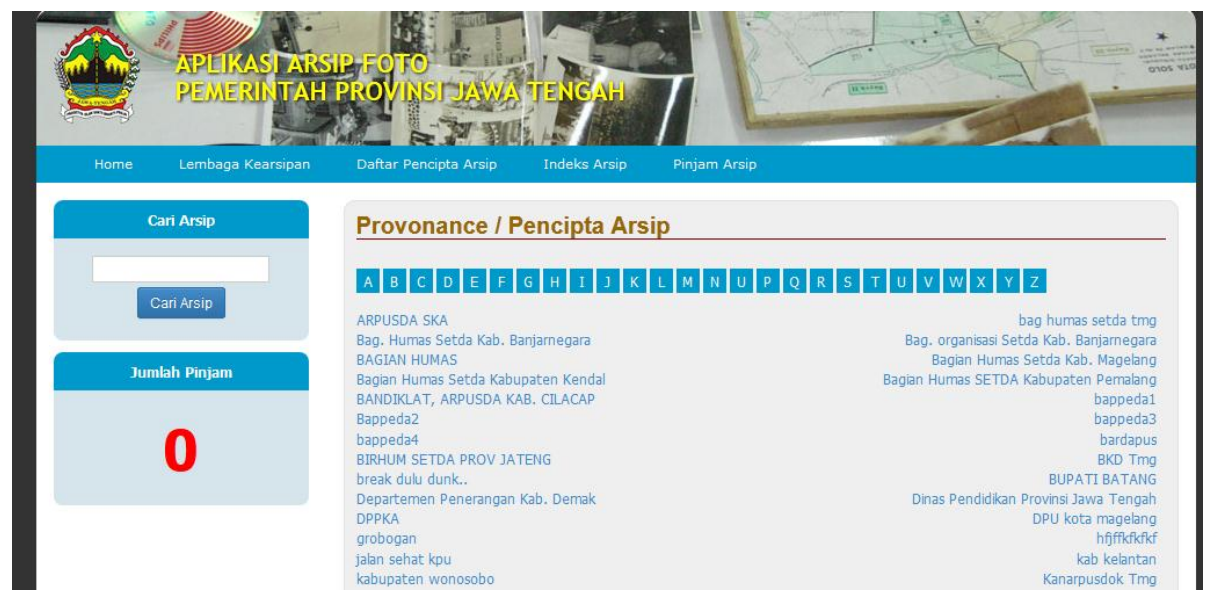


HUMANIKA Vol. 19 No. 1 (2014) ISSN 1412-9418

Arsip Foto Universitas Diponegoro sebagai Memori Korporat

Tri Handayani, Amin Taufiq Kurniawan

d. Halaman Indeks Arsip

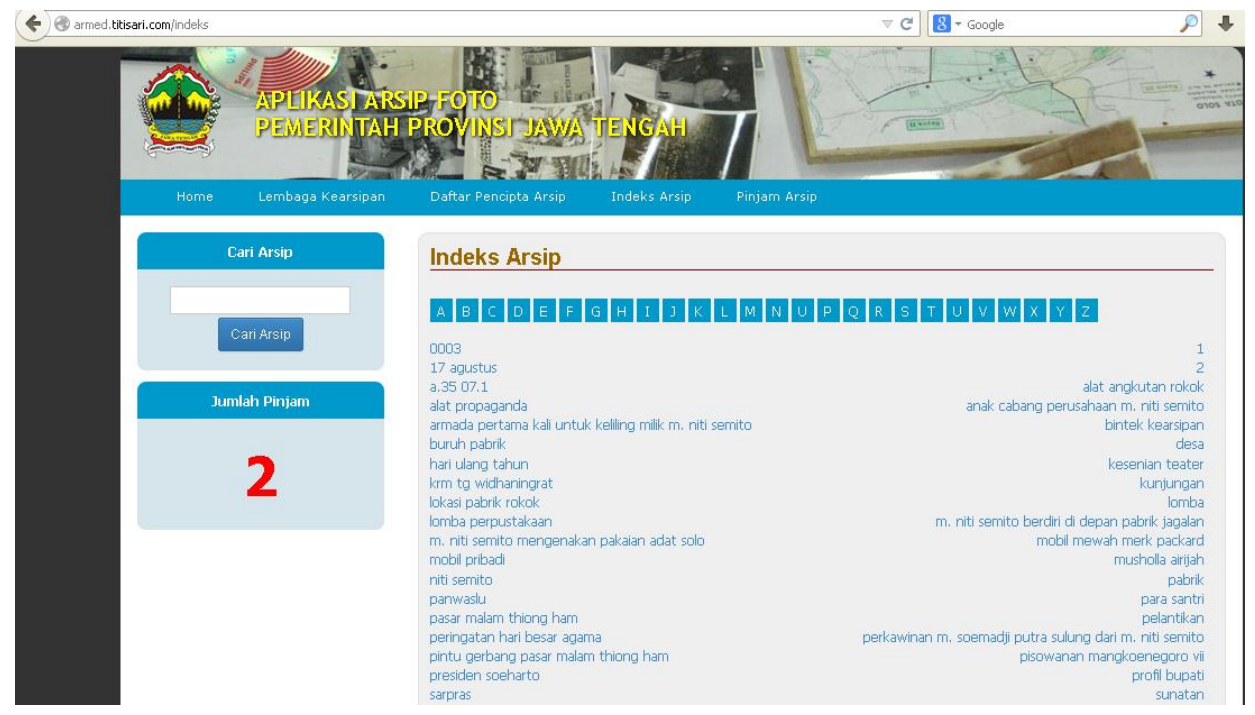

e. Aplikasi Peminjaman Arsip

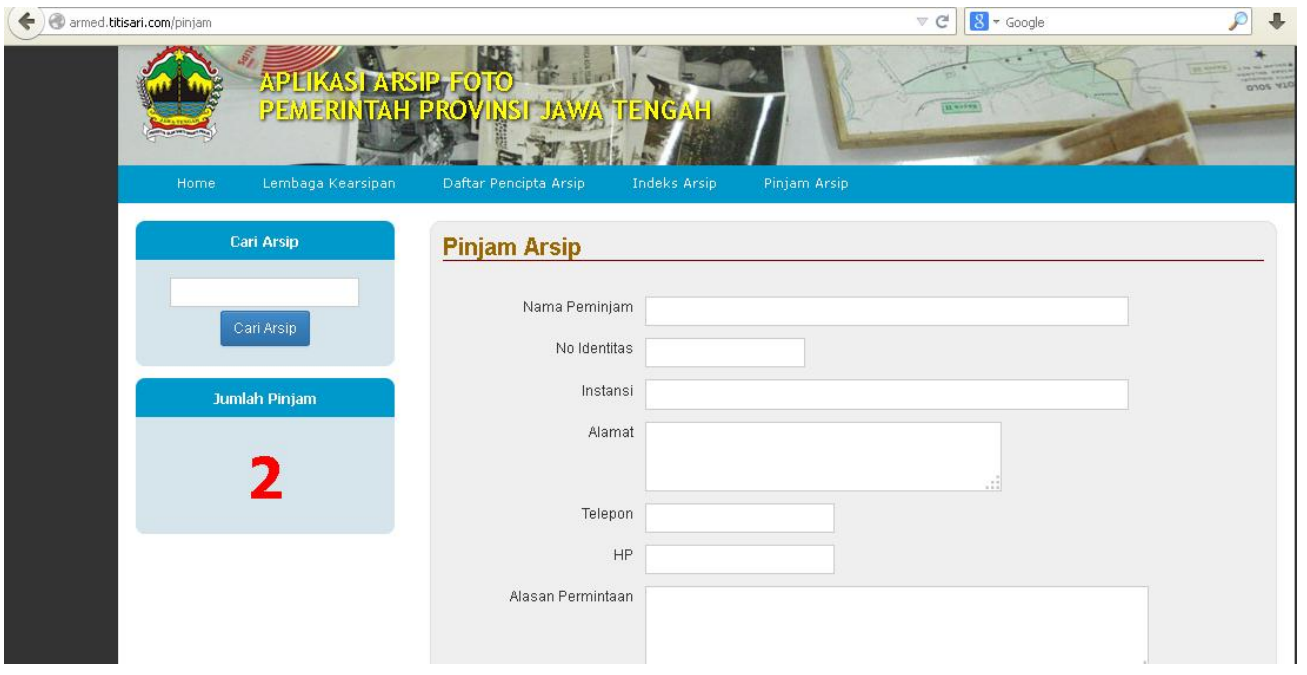


HUMANIKA Vol. 19 No. 1 (2014) ISSN 1412-9418

Arsip Foto Universitas Diponegoro sebagai Memori Korporat

Tri Handayani, Amin Taufiq Kurniawan

\section{Lampiran 2.}

\section{Daftar Informan}

1. Nama : Sriyati, S. Sos.

Pekerjaan : Kasubag Registik BAA Undip

Waktu : Rabu, 7 Mei 2014

2. Nama : J. Harry, S.Kom.

Pekerjaan : Staf Subbag UMPA FIB Undip

Waktu : Kamis, 8 Mei 2014

3. Nama : Dian Komalasari, S.Psi.

Pekerjaan : Kasubbag UMPA FH Undip

Waktu : Selasa, 6 Mei 2014

4. Nama : Lastur

Pekerjaan : Arsiparis Badan Arsip dan Perpustakaan Provinsi Jawa Tengah

Waktu : Jumôt, 13 Juni 2014

5. Nama : Kliwon

Pekerjaan : Programmer Badan Arsip dan Perpustakaan Provinsi Jawa Tengah

Waktu : Jumôt, 13 Juni 2014 